\title{
Identifying physics misconceptions at the circus: The case of circular motion
}

\author{
Alexander Volfson, ${ }^{1}$ Haim Eshach, ${ }^{1}$ and Yuval Ben-Abu ${ }^{2,3, *}$ \\ ${ }^{1}$ Department of Science Education \& Technology, Ben-Gurion University of the Negev, Israel \\ ${ }^{2}$ Department of Physics and Project Unit, Sapir Academic College, Sderot, Hof Ashkelon 79165, Israel \\ ${ }^{3}$ Clarendon laboratory, Department of Physics, University of Oxford, United Kingdom
}

(Received 17 November 2019; accepted 31 March 2020; published 2 June 2020)

\begin{abstract}
Circular motion is embedded in many circus tricks, and is also one of the most challenging topics for both students and teachers. Previous studies have identified several misconceptions about circular motion, and especially about the forces that act upon a rotating object. A commonly used demonstration of circular motion laws by physics teachers is spinning a bucket full of water in the vertical plane further explaining why the water did not spill out when the bucket was upside down. One of the central misconceptions regarding circular motion is the existence of so-called centrifugal force: Students mistakenly believe that when an object spins in a circular path, there is real force acting on the object in the radial direction pulling it out of the path. Thus, one of the most frequently observed naïve explanations is that the gravity force $\mathrm{mg}$ is compensated by the centrifugal force on the top of the circular trajectory and thus, water does not spill down. In the present study we decided to change the context of the problem from a usual physics class demonstration to a relatively unusual informal environment of a circus show and investigate the spectators' ideas regarding circular motion in this context. Thus, the goal of the present study is to examine the concepts of a heteroaged population regarding circular motion phenomenon provided in the context of a circus number as expressed in focus-group interviews following the number.
\end{abstract}

DOI: 10.1103/PhysRevPhysEducRes.16.010134

\section{INTRODUCTION}

There is general agreement today among physics educators that teachers' deep understanding of their students' knowledge is a necessary key step that might significantly help them in their efforts to design effective learning environments [1-5]. This view is expressed well by Vosniadou et al. [6] who write that teachers need to be informed about how students see the physical world and learn to take their points of view into consideration when they design instruction [6].

One way to identify students' knowledge about scientific concepts is the use of diagnostic tools (questionnaires, inventories) [1,7-9]. The other way is providing clinical interviews $[10,11]$. However, both ways are mainly limited to the study of solo cognitive, rather than sociocognitive aspects of knowledge. That is, both ways focus on the investigation of concepts and misconceptions of each subject individually. These methods do not relate the influence of the synergic interaction between individuals

\footnotetext{
Corresponding author. yuvalb@sapir.ac.il

Published by the American Physical Society under the terms of the Creative Commons Attribution 4.0 International license. Further distribution of this work must maintain attribution to the author(s) and the published article's title, journal citation, and DOI.
}

in social activities such as discussions, lessons, etc., which may result in the development of hybrid concepts [12]. Such concepts may be revealed in focus-group interviews and whole class dialogic discussions (WCDD) [13] while diagnostic tools and clinical interviews might miss them. Therefore, the third way is providing focus-group interviews. Indeed, focus-group interviews which in certain educational setups are conducted as WCDDs are known as an instrument to identify conceptual barriers (misconceptions) $[13,14]$ as we further explain.

Ponnambalam [15] argues that "the facts/laws of physics may be cold to many; but, the presentation of these laws can be very warm, lively, passionate - and even dramatic and poetic" (p. 393). The same, probably, can be claimed regarding the three ways for identifying physics knowledge. Indeed, while the classical clinical interviews and/or pen-andpaper questionnaires may seem dry and boring for some participants, sometimes even feeling as they are "doing a favor" for the researcher; focus-group interviews require, by their definition, the comfort and interest of the group members for engaging the discussion $[14,16]$. Therefore, speaking about physics concepts in a circus environment in the form of an entertaining quiz may definitely be such a "warm, lively, and passionate" way providing, on the one hand, a unique context for the interview questions, while, on the other hand, it is expected to be more pleasant and agreeable, thus promising a better cooperation of the participants. 
Circular motion is embedded in many circus tricks, and is also one of the most challenging topics for both students and teachers [17,18]. Previous studies have identified several misconceptions about circular motion, and especially about the forces that act upon a rotating object $[1,19,20]$. A commonly used demonstration of circular motion laws by physics teachers is spinning a bucket full of water in the vertical plane further explaining why the water did not spill out when the bucket was upside down. One of the central misconceptions regarding circular motion is the existence of so-called centrifugal force. That is, students mistakenly believe that when an object spins in a circular path, there is real force acting on the object in the radial direction pulling it out of the path $[1,19,20]$. Thus, one of the most frequently observed naïve explanations is that the gravity force $\mathrm{mg}$ is compensated by the centrifugal force on the top of the circular trajectory and thus, water does not spill down [20].

In the present study we decided to change the context of the problem from a usual physics class demonstration to a relatively unusual informal environment of a circus show and investigate the spectators' ideas regarding circular motion in this context. One of the authors (A. V.) is also a circus artist performing a number ${ }^{1}$ that includes rotation of two bowls filled with water and connected by a rope as we further explain. The physics of the number is identical to the one of the bucket experiment. Thus, the goal of the present study is to examine the concepts of a heteroaged population regarding circular motion phenomenon provided in the context of a circus number as expressed in focus-group interviews following the number. In what follows, we first outline the theoretical framework regarding naïve knowledge and misconceptions for this study; second, we briefly summarize the literature on focus-group interviews; and finally, we bring a brief overview of the centrifugal force idea.

\section{LITERATURE REVIEW}

\section{A. Theoretical framework for students' concepts and misconceptions}

One of the theories explaining naïve knowledge of students is that of diSessa. diSessa views naïve knowledge as fragmented and loosely coherent [21]. According to diSessa's theory, naïve knowledge consists of phenomenological primitives ( $p$ prims), which are elements of knowledge that constitute people's "sense of mechanism," their sense of which happenings are obvious, which are plausible, which are implausible, and how one can explain or refute real or imagined possibilities [22] (p. 69). They are

\footnotetext{
${ }^{1}$ Classical circus shows are composed of relatively short parts. Each part usually presents a different art (acrobatics, juggling, equilibristics, etc.) and called a "number." A certain exercise in a number is called a "trick."
}

called primitives because they appear self-evident and irreducible; they constitute explanatorily primitive descriptions of events. A person merely assumes that "something happens because that's the way things are" [23] (p. 112). They are called phenomenological because they are rooted in experience. $p$ prims do not have the status of a theory because they are not produced or activated under a highly organized system like the framework theories proposed by knowledge-as-theory perspectives such as the theories of Chi $[24,25]$ and Vosniadou $[6,26]$. These $p$ prims are generated from a learner's experiences, observations, and abstractions of phenomena.

$p$ prims are usually activated when interpreting scientific phenomena. By this view, how students respond to a question depends on which $p$ prims are activated; while activation of a certain $p$ prim heavily depends on the context of the problem [21,23]. "In more technical detail, thinking in different contexts typically involves different knowledge (different noticing and different inferences), which may need to be acquired separately for different contexts" [22] (p. 75). To stress the influence of context on students' answers, diSessa, Gillespie, and Esterly [27] describe Ranney's study [28,29], which investigated subjects' predictions across isomorphic situations. In one case, when comparing a pendulum bob release versus the release of a human (trapeze artist) in midswing, only $20 \%$ of subjects gave matched predictions to the two situations. Even when subjects professed isomorphism (pronounced the situations "fundamentally similar"), only $31 \%$ of their drawn predictions of trajectory were the same for both cases. diSessa further argues that describing the meanings that students assign to specific concepts requires a huge number of individual "pieces" $[21,23]$. Since every person is likely to own a different array of $p$ prims due to their personal experiences, one can also expect, according to diSessa, to observe a relatively wide and unpredictable range of explanations for the same physical phenomenon presented in the same context among a group of objects. Similarly to Ranney [28], in the present study we change the context of the problem from a usual physics class demonstration to a relatively unusual informal environment of a circus show and investigate the spectators' ideas regarding circular motion in this context.

\section{B. Focus-group interviews}

Focus-group interviews are one of the valuable tools for collecting qualitative data [30]. As compared to other techniques of data collection, e.g., questionnaires, observation, etc., a focus-group interview may serve as a rich source providing information about a range of ideas and feelings that individuals have about certain issues, as well as illuminating the differences in perspective between groups of individuals [14].

A focus group interview is a group discussion designed to obtain perceptions focusing on a specific area of interest 
in a nonjudgmental and nonthreatening atmosphere. Group members should feel relaxed and comfortable, and enjoy sharing their ideas and perceptions [16,30]. Circus art "excites, amazes, and delights" [31] (p. 1). It captures the imagination of most children as well as adults, bringing to audiences the human beauty, courage and passion, glitter and glamour, and making the spectators laugh and worry, feel and think, intermittently. Therefore, the circus environment can definitely be considered as one that arises interest and is comfortable at the same time, thus providing a suitable atmosphere for focus-group interviews.

While personal interviews aim at studying in detail the perceptions of each participant individually, focus group interviews have the potential of revealing additional views due to their ability to generate data based on the synergy of the group interaction [14]. Indeed, Eshach [13] argues that when individual participants share some of their ideas with their colleagues in a full class discussion format under the teacher's guidance, these ideas may influence one another, develop each other, and transform into new ones. Indeed, according to Vosniadou's framework theory [32], when dealing with a scientific phenomenon, students use old and new information, which can result in hybrid concepts, sometimes created on the spot. Therefore, because of the influence of the synergic interaction between group members, participants may develop hybrid concepts themselves. Such concepts, therefore, may be revealed in group interviews while clinical interviews would miss them. Since our goal in this study is to identify as rich as possible a diversity of views, we chose to conduct group interviews. The "group" in this research is actually the audience of a circus show, and the interviewer is the artist.

\section{Circular motion and centrifugal force}

Actually, the concept of centrifugal force is not "criminal." It is related to the d'Alembert (1717-1783) principle, which leans on the base of the kinethostatics approach in theoretical mechanics and engineering. The main idea of kinethostatics is that dynamic problems can be reduced to static ones by defining so-called inertia forces [33,34]. Let us look at a point mass $m$. Because of Newton's second law the vector sum of forces is equal to the product of $m$ times the vector acceleration $\sum \vec{F}=m \vec{a}$. This is a dynamic equation. We can transform it to a static one by defining the inertia force as $\vec{J}=-m \vec{a}$. This trick indeed turns the problem to a static, ostensibly suitable to Newton first law, thus, obeying the equation $\sum \vec{F}+\vec{J}=0$.

As to circular motion, one can define the inertia force to be $J=m v^{2} / R$ (Figure 1). This force supposedly acts in the radial axis direction out of the circular path; therefore, it is called centrifugal force (from the Latin centrum, meaning "center," and fugere, meaning "to flee"). It is pretty attractive to use the idea of centrifugal force when dealing with uniform circular motion problems. Let us for instance

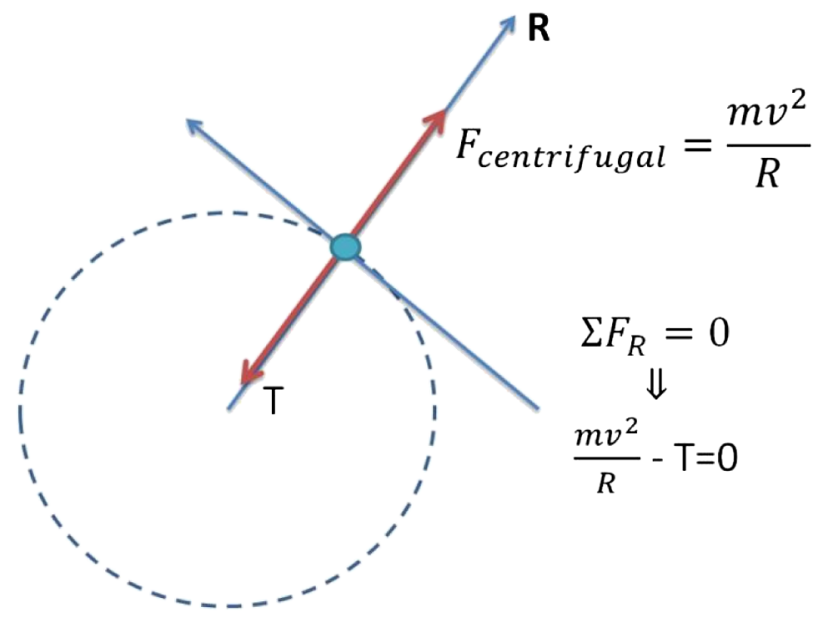

FIG. 1. Viewing centrifugal force as a real force acting on the spinning ball leads to the correct equation but is likely to produce misconceptions.

look at a tennis ball of mass $m$ tied to a rope of length $R$ and rotated uniformly by a boy in a horizontal plane. The ball stretches the rope, so intuitively the boy can conclude that there is a force pulling it out. This way of thinking probably belonged to Christian Huygens (1629-1695) who was the first to coin the concept of centrifugal force [18]. As to the ball, its radius of spin is constant. Thus, one can consider that the ball is found at rest on the radial axis. Therefore, due to Newton's first law, the resultant force acting on it is zero, i.e., $m v^{2} / R-T=0$. Although the static equation leads to the correct solution, namely, $T=m v^{2} / R$, it can be very tricky and produce misconceptions.

Probably due to confusion over the d'Alembert principle, centrifugal force is figured out by some authors even in not too old physics textbooks as a real force. This is a typical citation: “... a body deviating from the straight path develops a centrifugal force of inertia" [35] (p. 74). Such formulations are more than likely to produce misconceptions. Indeed, several generations of physics teachers and their students still hold this idea of centrifugal force $[1,18]$. The present study results, in a sense, to reinforce these findings. However, according to the theory of diSessa and the characteristics of focus-group interviews we expect to identify more than one misconception about circular motion.

\section{RESEARCH AIMS AND QUESTIONS}

The present study aims to examine the heteroaged public understanding of circular motion physical principles as expressed in focus-group interviews conducted during or after a circus show. The following questions guided our study:

(a) What are the participants' (children and adults) concepts of circular motion as expressed in the circus focus-group interviews? 
(b) What are the possible experiences that these concepts are rooted in, as can be deduced from the focus-group interviews?

\section{METHODOLOGY}

\section{A. The study population}

During the years 2014-2015, 14 shows were conducted by the Israeli KESHET (rainbow in Hebrew, and also an abbreviation of Circus of Peace and Hope) circus artists. During (or right after) each show, a focus-group interview about the underlying physics explaining the circular motion embedded in the circus tricks was conducted, led by the performing artist. Seven shows took place in a hotel on the Dead Sea in Israel. About 50 spectators of various ages watched each show. Of these, 10 to 20 people remained after each show and participated in a discussion about 15 min long (about 105 people in total). The other shows were as follows: 2 in summer camps, 2 in a science museum, 2 in youth circus studio rehearsals, and one in a community event. In total, about 750 people watched the shows. From them, 173 actively participated in the focus-group interviews. These interviews were video recorded and transcribed verbatim.

\section{B. Focus-group interviews in the circus environment}

Denscombe [36] outlines three distinctive characteristics of focus-group interviews. In what follows we demonstrate how these characteristics come to fruition in circus focusgroup interviews:

a. Prompt or stimulus: The sessions usually revolve around a prompt, a trigger, some stimulus introduced by the moderator in order to focus the discussion.

One of the artists, being one of the present study's authors (A. V.), is also a physics teacher with extensive experience in conducting focus-group interviews and whole class dialogic discussions. One of his numbers includes the following trick: the artist spins two open bowls, connected by a rope and filled with water, round and round, combining vertical and horizontal planes of rotation, spinning in "eights" etc. (see Fig. 2). The water does not spill out (see Fig. 2).

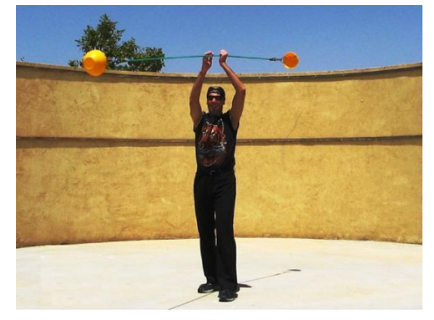

(a)

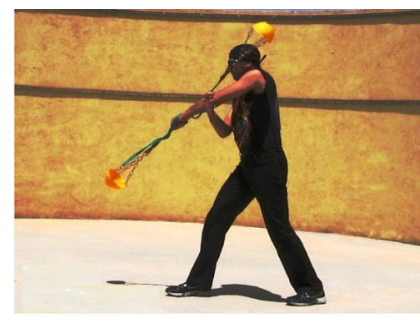

(b)
FIG. 2. (a) The artist spins two bowls filled with water in a horizontal plane. (b) The artist spins two bowls filled with water in a vertical plane.
Following this number, the artist put the bowls down, and asked the audience to

- Explain why the water did not spill out of the bowls;

- Predict what would have happened to the bowls if the rope were to tear during their motion at some specific point (in the horizontal plane, when one of the bowls is in front of the artist, and in the vertical plane when the bowl is on the top).

b. Moderator-not a neutral person: There is less emphasis on the moderator to adopt a neutral role in the proceedings than is normally the case with other interview techniques.

The artist not only provided verbal prompts during the interviews, but rather used circus demonstrations to further challenge the participants' view in cases he felt were needed. At eight of the shows the artist announced that the correct answers would be awarded by a prize. At three shows the artist rewarded with prizes every novel and scientifically considerable answer-that is, not necessarily the correct one, but every answer that suggests a "theory" explaining all the provided demonstrations and developing or rejecting previous explanations of the other participants. And at the other three shows the artist did not offer any reward at all. The reward turned the discussions into a kind of a game or quiz and, thus, facilitated the cooperation of participants and contributed to the atmosphere of entertainment.

c. Interaction within the group: Interaction between group members is given a particular value rather than just gathering opinions of people. The collective view is given more importance than the aggregate view.

Along with the above, the artist did not just enable the participants to reveal their own ideas, but actively stimulated participants to relate others' ideasdeveloping, confronting or rejecting them, creating hybrid ideas, and sharpening their own ones; saying, for instance, "This guy thinks that the water doesn't spill out because ..., the girl argues that ..., and what do you think?", "How would you deal with his idea? How do you know that he is not right?", "Who can explain in more details her idea?" and so on. Once the participants expressed their ideas, the artist summarized the discussion and explained, in a qualitative manner, the underlying physics of the circus number. He began with explanation about Newton's first law and then explained that at every point of the path, each bowl "strives" to continue moving in a straight line in a tangent to the path direction, but since the rope holds it, it is forced to move in a circular path, due to the action of centripetal force (tension of the rope in this case). The water in the bowl also strives to continue moving in the tangent direction, however, it is blocked by the bowl, which exerts a force on the water. This makes the water stay in the bowl. The artist also emphasized that there is no centrifugal force, but on the contrary, there is a force which pulls the bowls 
to the center of the circular motion path-centripetal force, tension in this case. The artist explained all these in laymen's terms, without using any formula.

\section{Data analysis}

The focus-group interviews were videotaped and further transcribed verbatim. In order to identify participants' views of circular motion, an inductive analysis was performed on the transcriptions by the authors (a professor of science education with 15 years of experience, a Ph.D. physics teacher and lecturer with 12 years of experience, and a Ph.D. physicist and lecturer with 20 years of experience). The analysis process went through the following five steps according to Eshach and Schwartz [37] as well as Fridell and Ekberg [38]:

a. First reading of the transcribed data to obtain a comprehensive overview [39].

b. Subsequent readings by each researcher individually searching for certain themes or patterns (of misconceptions as well as correct explanations) across a (entire) dataset forming the categories [40].

c. Rereading the data by the authors together to confirm the categorization process.

d. Association of the various items of meaningful content found in the texts with the relevant categories, coding. The coding process was done along the lines of that used by Slotta, Chi, and Joram [41] as well as Eshach and Schwartz [37]. It consisted of identifying keywords or sentences that reflected one of the views discussed in the next section. For instance, a sentence like "A force pushes the water out and you blocked the water!" reflects the centrifugal force misconception.

e. Review of the categorization to ensure that it reflects the relevant concepts. Certain ideas were recategorized at this stage.

This analysis yielded three main views of circular motion as described in Sec. V.

\section{RESULTS}

Only about $2 \%$ of the participants provided a correct explanation for why the water stayed in the bowls. While among the misconceptions revealed, the centrifugal force idea was the most often expressed $(\sim 40 \%)$, especially among the adult participants. It should be noted that others in the audience probably held this view as well, although they did not express it regarding the first question. Indeed, $56 \%$ further predicted that a bowl, when released, will fly in a radial direction, outside the circle trajectory of motion; and 5\% said outside in a diagonal direction; that is, $61 \%$ obviously rooted their predictions in the idea of centrifugal force as we explain below. As it was said, prizes were handed out in 11 of 14 shows. Nevertheless, we observed no influence of handing out or not handing out prizes on the suggested explanations as well as their variety.

\section{A. Views regarding the question: Why did the water not spill out? \\ 1. Centrifugal force (40\%)}

According to this view, when we spin an object, an actual centrifugal force appears and pushes the object outside of the path, in a radial direction $[1,19,20]$. This centrifugal force pushes the water to the bottoms of the bowls and thus it does not spill out. It should be noted that those who expressed the centrifugal force view (a) considered it as a real force, and (b) could not go much beyond using the term "centrifugal" to explain why the water does not spill out. Also, many of those who expressed this view believed that centrifugal force depends on the rotation speed; i.e., the faster one spins an object the stronger is the centrifugal force acting on it. This argument was expressed especially to address why the water does not spill out in a vertical plane rotation. Here is a typical part of an interview:

Artist: This is the moment that I will be glad to hear your answers to the question, why did the water not spill out? Scientific answers will be awarded by a special circus prize!

Participant 1: Centrifugal force.Artist: Participant 1 said "centrifugal force." Who can explain this term? Participant 2: The water defies gravity because you spin it fast.

Participant 3 (adult): Centrifugal force says that when you spin an object there is force acting from the center outside, and as a result the object is pulled outside. It's like when we travel in a car, we are pushed outside in road bends. The water is pushed to the bowls in the same way.

Artist: What is this centrifugal force? Why does it exist? Can you explain?

Participant 3: When the gravity vector pulls the water down (when a bowl is upside down), the pulling outside vector would be stronger.

Artist: So, centrifugal force is a vector pulling the water outside?

Participant 3: Yes!

\section{Speed of spin (27\%)}

Those who expressed this view referred primarily to the case of spinning the bowls in a vertical plane, although in the show the artist rotated the bowls both vertically and horizontally. According to this view, the artist spins the bowls so fast that the water actually does not have enough time to spill out when the bowls are overturned on the top of their path. This view should not be confused with the view connecting the speed of spin with the centrifugal force described in the previous section. According to the previous view, rotation speed influences the magnitude of centrifugal force, whereas according to the view presented 
in this section, the speed of rotation cuts down the time that water needs to spill out. Another variation of this idea is that the water does spill out, but the artist spins the bowl so quickly that he manages to catch the water back at the bottom part of their trajectory. This variation was mostly expressed by the young children in the audience. Here is a representative part of an interview:

Artist: Why did the water not spill out?

Participant 4: You twisted it fast.

Artist: So?

Participants 4 and 5: The bowls caught the water.

Artist: We need some more explanation here... Who can help us?

Participants 6 and 7 together: You spin it fast. The water doesn't have time to get out and fall because of the gravity.

At this point the artist usually challenged the participants by spinning the bowls in a horizontal plane only. This way he contradicted the speed of spin idea as follows:

Artist: And what if I spin the bowls only in the vertical plane? Demonstrates.

Participant 8: In the vertical, the water does not have enough time to spill down.

Artist: And if I spin the bowl horizontally, the water still does not have time to spill? How? The bowl is almost on its side all the time... Demonstrates.

Participant 8: So it's the centrifugal force in both of the cases.

\section{Air pressure (15\%)}

Pressure resulting from fast motion of the water relative to the air. According to this view, when we spin the bowls

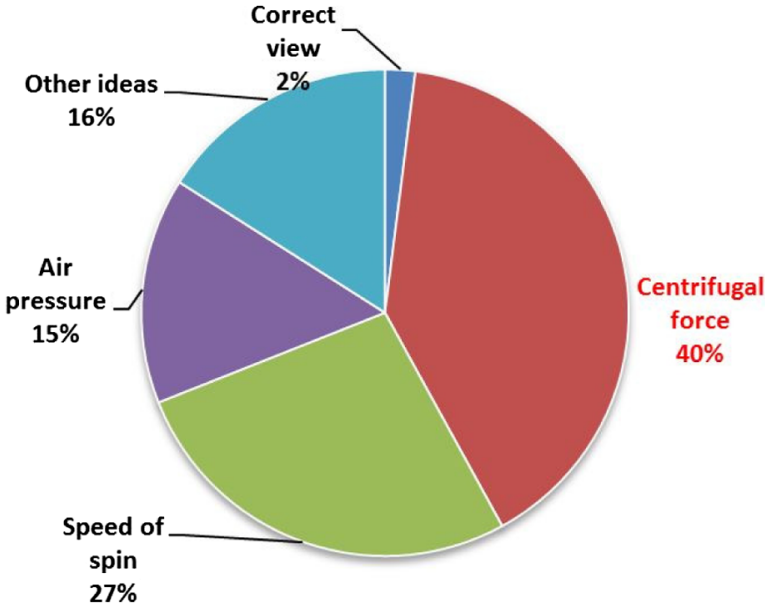

(a) quickly enough the air exerts an increased pressure on the water. This pressure keeps the water inside the bowls. Some participants explained that there is a friction between the water surface and the air. This friction also pushes the water into the bowls. This view was expressed by adult as well as adolescent participants. Here is an example:

Artist: Why did the water not spill out?

Participant 9: You twisted it fast.

Artist: So?

Participant 10: It's the air pressure!

Participant 11: The air pushes the water to bowls when you spin them.

Or, as participant 12 argued in another interview: "The wind pushed the water inside the bowls." As to the idea of friction with the air, participants 13 and 14 in two other shows argued that: "Friction with the air keeps the water inside." and "Air friction! The air presses the water inside". As one can see, these participants confuse air pressure, which should act perpendicularly to the water surface, and friction force, which is always parallel to the surface and thus cannot press the water inwards the bowls.

The correct view (2\%) was actually expressed by 2 participants: a high school physics student who had just finished his matriculation exams (Dead Sea hotel) and a 10-12 year-old boy who explained: "If you throw a ball, it would fly in a straight line. If there is a rope, it forces it to spin in a circle. The same is about the water."

Other naïve ideas (16\%) were expressed, mostly by little children, such as: "there is a trick"; "you put some special material in the water"; or "because you're doing a circus," etc. According to our knowledge views 2 and 3 have not been figured out in the professional literature yet. Figure 3(a) summarizes these findings.

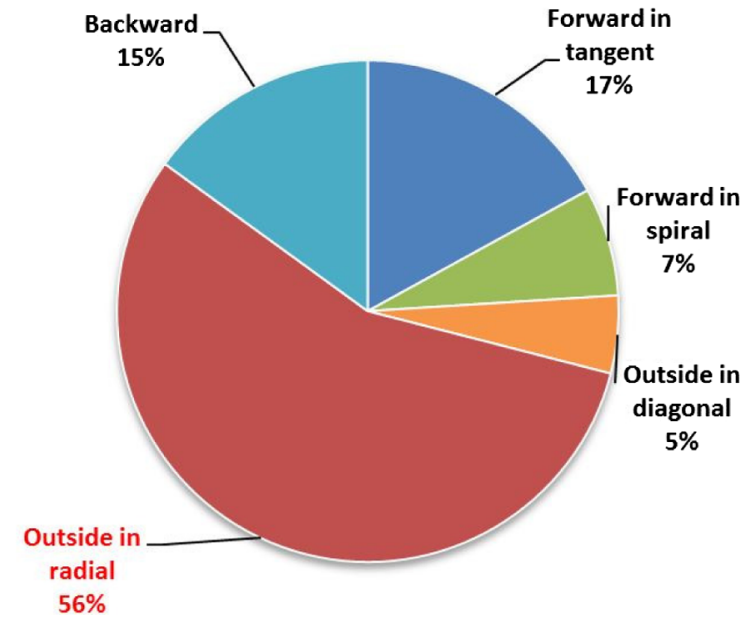

(b)

FIG. 3. (a) (left) Distribution of responses regarding the question: Why did the water not spill out? (b) (right) Distribution of responses regarding the question "If the rope holding the bowl suddenly tears, at what trajectory will the bowl fly?" 


\section{B. Views regarding the question: If the rope holding the bowl suddenly tears, at what trajectory will the bowl fly?}

Our results reinforced the findings of Hestenes et al. [1], and also revealed a new misconception ( 3 below). The participants answered that the bowl would continue

1. Outside in a radial direction (56\%).-According to this view, due to the circular motion, there is real centrifugal force acting on the object in a radial direction. This force pushes the rotating object "outside" in a radial direction. This view of real centrifugal force pushing objects outside shall be considered as the most robust in the terms of Chi [42] and persistent even for directly contrasting demonstration-for instance, spinning and releasing the bowl which continues to fly in a tangent and not radial direction. Here is a part of a dialogic discussion which the artist conducted in a physics teachers' conference. The participant is a senior high school physics teacher with more than 20 years of experience. The artist has performed the bowls' number in front of the teachers and showed by spinning and releasing a bowl that there is no centrifugal force. He emphasized that if there was such a force, the bowl should continue flying outside of the circular trajectory and not in a tangent direction as it really happens.

Teacher: What do you mean, there is no centrifugal force?! Of course, there is centrifugal force! You just feel it when you spin an object. Try to revolve in a carousel; you will feel it very well! Artist: But we have just seen that the bowl flies in tangent and not outside. Does centrifugal force "know" that I release the rope and it should stop acting?

Teacher: Centrifugal force acts only on spinning objects. Once an object stops rotating, centrifugal force stops too.

Artist: So, what is the nature of this centrifugal force? Is it gravitational, electro-magnetic, nuclear...?

Teacher: No! It is inertial force.

Artist: What do you mean by "inertial"?

Teacher: Enough this nonsense! After all, when you spin a phonograph disc and put a coin on it, you can see clearly how the coin slides outside in a radial direction ${ }^{2}$ !

\footnotetext{
${ }^{2}$ This is definitely not true! If one spins the disc slowly, it can be seen that the coin strives to slide in a tangent direction, when at every point the friction with the grooves causes its trajectory to be a spiral. When spinning the disc quickly, the coin passes between the grooves very fast and there is an illusion that it slides in a radial direction.
}

2. Forward in a tangent to the circular path direction $(17 \%)$.- This is the correct answer.

3. Backward (15\%).- This idea was mostly expressed by the young participants (younger than 10 years old). As one of the children explained: "Because it (the bowl) rotated forward. The rope tore and the bowl would fly backward."

4. Forward in a spiral (7\%).--Hestnes et al. [1] called this idea "circular impetus." This is to say, an object leaving a circular path for some reason will continue to spin in an expanding spiral.

5. Outside in a diagonal direction (5\%)-Those who held this view explained that combining the centrifugal force, which is in an outside direction, and the velocity, the direction of which is tangential to the circular path, yields the diagonal direction. Figure 3(b) summarizes these findings.

\section{DISCUSSION}

The present study aimed at examining the general, heteroaged public understanding of circular motion physical principles as expressed in focus-group interviews conducted in the context of circus shows. The focus-group interviews revealed several misconceptions about circular motion. While some of these misconceptions were already described in the literature others had not yet been described. It seems that since known misconceptions as well as some misconceptions that were not yet been described in the literature were revealed in this study, the suggested circus focus-group interviews may have the potential to be used as a diagnostic research tool by researchers, as an addition to the ones that already exist in a variety of topics in physics.

This study was carried out in an informal setting, the discussions were conducted as part of entertainment activity, and giving prizes is one of the traditions associated with this environment. Therefore, in order to cheer the conversation and attract the audience at some of the shows the artist handed out prizes for the correct answers; at some others, to encourage the expression of ideas, the prize was not given only to those who expressed the correct answer, but also for those who came up with a novel and reasonable idea; at the rest he did not offer any reward. The reward turned the dialogic discussions about circus tricks (DDCT) into a kind of a game or a competition and thus facilitated the cooperation of participants and contributed to the atmosphere of entertainment. The fact that no difference, neither in the suggested explanations nor in their variety or frequency, was observed in these shows teaches us that the answers obtained in the research reflect true misconceptions (i.e., really deep-seated ideas about how the physics works) and not some "making up" answers excogitated just to participate and get a prize. In what follows, we will first discuss the three main ideas revealed: Centrifugal force, speed of spin, and air pressure, as well as the possible thinking mechanisms and experiences that could lead to 
these ideas. Second, we shall review the knowledge in pieces theory of diSessa [22] relative to the present study results.

\section{A. Misconceptions regarding circular motion-why and how? \\ 1. Centrifugal force}

Among the misconceptions revealed, the centrifugal force idea was the most expressed ( 40\%), especially among the adult participants. It should be noted that others in the audience probably held this view as well, although they did not express it during the discussions; indeed the outside in radial and outside in diagonal ideas were argued by $61 \%$. What are the possible roots of this $p$ prim? Let us look, for instance, at a boy pulling a rope with his friend. He feels the force applied by his opponent and applies his own force-tension-in an opposite direction. Both forces act along the rope and stretch it. The same is experienced when one spins a ball connected to the end of the rope. The tension of the rope is felt well. Thus, it is easy to consider that there is an opposite of the tension force "pulling," just like the boy's friend, the ball outside along the rope. Another experience reinforcing this view could be found in the explanation of participant 3 cited previously: "It's like when we travel in a car, we are pushed outside in road bends" making the idea of centrifugal force even more tempting. Let us look once more at the bowls number. Before spinning the rope to which the bowls were connected, the rope was not stretched. As a result of spinning the rope with the bowls, it stretched. Such a situation goes hand in hand with the wrong view of centrifugal force. The other common misconception expressed in the discussions, concerning the direction of the bowls' movement when the rope will be released, namely, that the bowl would fly in a radial direction; seems to be a logical continuation of the centrifugal force idea.

Similar ideas were expressed by Huygens (1629-1695), who was the first to suggest the concept of centrifugal force [18]. Thus, our findings provide further support for the notion expressed by many researchers that there is a degree of parallelism between today's naïve views and ideas of classical and medieval scientists and philosophers [37,43-45]. However, this idea of centrifugal force cannot be related only to naïve ideas. After all, there were also adults in the audience, who had studied physics. Indeed, it seems that in relatively old physics textbooks, centrifugal force is presented in such a way that naïve students may interpret it as an actually existing force (see, for instance, Putilov [35]). This might be especially the case with the adults in the audience, as we saw in the discussion with the senior teacher, who learned from such books and children who were taught by their parents or teachers in the same way bringing the cultural aspect to the story. Appropriate demonstrations and discussions that surrounded circus tricks usually allowed us to challenge this view.

\section{Speed of spin}

According to this view, the bowls spin so fast that the water does not have enough time to fall. To the best of our knowledge, this idea was not yet described in the literature. Which $p$ prim might be responsible for this view? diSessa brings some examples for "comparison" $p$ prims, such as increased effort begets greater results; the world is full of competing influences for which the greater "gets its way," even if accidental or natural "balance" sometimes exists [22]; closer means stronger [46], etc. In the same manner, our everyday experience might tell us that if we do something quickly enough, something else would not have sufficient time to occur. For instance, if one runs fast enough to catch a ball, the ball would not have sufficient time to fall to the ground and probably would be caught. It might be that the context of the certain number led the participants to this way of thinking. After all, the artist indeed rotated the bowls very fast. As participant 8 said, "In the vertical [plane], the water does not have enough time to spill down." Or, in the other, more childish version-the artist spins the bowls so fast that also the water actually spills out, the artist succeeds to catch it so the water does not have enough time to reach the ground.

It is interesting to note in this regard that in some circus teaching sources the same views regarding the speed of the circular motion and it being fast enough so as to not allow the water to fall may be found. For instance, Bauman [47] in his "Art of Juggling," when introducing the present trick of twisting two cups (bowls) connected with a rope filled with water inside, wrote "If you rotate the rope fast, the water will not have enough time to spill out" (p. 105). This also shows that "speed of spin" misconception is not typical only for children but is also held by adults.

\section{Air pressure}

Another idea that was not yet described in the literature is that, due to the circular motion, there is an air pressure that pushes the water to the bowls, not letting it spill out. Again, this might be explained by the context of the circus. Almost everyone has experienced the air pressure on their face when traveling a car with an open window, or riding a bicycle fast. As we move faster, we experience greater air pressure and its resistance (friction). As participant 11 argued "The air pushes the water to bowls when you spin them." On the other hand, fast rotating bowls tied to a rope produce a rustling sound which also might be associated with air friction, and therefore, air pressure as participants 13 and 14 suggested.

Some of the misconceptions identified in this study were actually combinations of other ideas that were expressed during the DDCT. These are called hybrid or synthetic models $[6,26,48]$. An example of this is that based on the ideas expressed in the DDCT some participants reached the view that the water does not spill out because of both the air pressure and centrifugal force. Indeed, according to 
Vosniadou [12] synthetic conceptions are not unitary, faulty, and unchanging "specific theories," but are malleable mental models, adaptable to contexts and situational changes and often constructed on the spot. Another example of a synthetic model was the outside in a diagonal direction idea, bringing together the effects of centrifugal force outside and the velocity which is tangent to the circular path, as some of the participants explained. Those who expressed this view probably had in mind what they learned at school about vectors. Of course, in this case one cannot add the velocity vector and force vector.

\section{B. Diversity of $\boldsymbol{p}$ prims is limited}

diSessa [22] emphasizes that "an immediate consequence of the existence of rich, small-scaled knowledge ( $d$ prims) is that there are many dimensions of potential difference among learners. Each learner may have a different subset of the whole pool of "little" intuitions, and might treat common elements rather differently" (p. 68). This is to say, every individual is expected to have his own set of $p$ prims and thus one might expect much richer variety of views in the same context- the number with bowls, than the only three identified. After some shows these views were quite predictable and fully repeated at almost every show. It seems that the centrifugal force idea had even the status of a naïve theory or, framework theory in the terms of Vosniadou. Implementation of this "centrifugal theory" by the participants provided the mistaken predictions regarding a bowl's path if it is released-outside in radial and outside in diagonal. How though, can this fact be explained in the terms of the knowledge in pieces theory of diSessa?

$p$ prims are generated from a learner's experiences, observations, and abstractions of phenomena. diSessa [23] emphasizes the body principle according to which "agency, (muscle) tension, and so on are likely to be represented in ... p prims" (p. 123). Thus, the ensemble of $p$ prims of each individual is formed by the experiences and observations one undergoes in their life. Obviously, this ensemble is mostly dictated by the culture of the society that the individual lives in. Therefore, when a sample of individuals comes from the same culture, one can expect them to be of almost similar ensembles of $p$ prims. Consequently, actually a limited number of $p$ prims will be activated in every given context. These $p$ prims, the conditions for their activation as well as their further implications by individuals, can be learned and taken into account when preparing relevant educational activities.

\footnotetext{
${ }^{3}$ That is, knowledge acquisition process-a phenomenon analysis, in our case-entails developing a naïve physics that does not consist of fragmented observations but rather forms a relatively coherent explanatory system-a framework theory [32].
}

\section{CONCLUSION AND FUTURE RESEARCH DIRECTIONS}

The fact that a large portion of those who came just to watch a circus show remained and actively participated in the discussions shows that circus offers a unique nonformal environment for providing comfortable and interesting focus-group interviews as the literature requires $[14,16]$, thus promising a better cooperation of participants. Furthermore, it is the competitive atmosphere that motivated the children and adult audience to participate in the discussions. Indeed, the artist conducted 7 such discussions in a hotel, which was full of various competing enjoyable stimuli such as concerts, dance pole, bar, etc.; nevertheless, a relatively large portion of the audience stayed for $15 \mathrm{~min}$ after the shows to participate in the discussions. It was clear that the competitive atmosphere helped tremendously.

At the end of every interview the artist summarized the discussion and explained, in a qualitative manner, the underlying physics of the circus number. Such circus interviews or discussions provided by the artist had actually most of the characteristics of whole class dialogic discussions as specified by Eshach [13]. Indeed, every discussion provided by the artist had the IRPE pattern of interaction, that is,

1. Initiation.- demonstration of the number and inspiring a discussion by an open question: why did the water not spill out?

2. Responses. - the participants speak and the artist listens.

3. Prompts. - the artist encourages participants to express their ideas, commends participants, if necessary asks for clarifications, sometimes provides challenging prompts and appropriate demonstrations widely using the suitable circus equipment.

4. Evaluation.-Here the interview is over. The artist summarizes the discussion and presents the correct explanation or, if one of the participants has already said the correct answer, clarifies it.

Thus, the suggested circus interviews or discussions can provide not only a diagnostic instrument, but also an original and promising pedagogic direction in bringing advanced scientific ideas to the general public via dialogic teaching in ways that are relatively easy to understand for those without a physics background. It does not require, of course, that every physics teacher should be a professional circus artist. Physics teachers can expose their students to the world of circus by bringing some simple circus equipment to the classes, taking students to circus shows and/or master classes, or analyzing certain circus tricks presented in a video. Therefore, developing and exploring group dialogic discussions about circus numbers integrated in circus shows, as well in circus master classes and lessons regarding a variety of physics concepts, will be the focus of our next studies. 


\section{ACKNOWLEDGMENTS}

We would like to extend our gratitude to Marina Aletko, Valeria Shparaga, and Maria Dragilev, artists in the KESHET Circus, for their cooperation in the present research.

[1] D. Hestenes, M. Wells, and G. Swackhamer, Force concept inventory, Phys. Teach. 30, 141 (1992).

[2] I. Galili and A. Hazan, Learners' knowledge in optics: interpretation, structure and analysis. Int. J. Sci. Educ. 22, 57 (2000).

[3] D. F. Treagust, Conceptual change as a viable approach to understanding student learning in science, in Teaching and Learning Science: A Handbook (Rowman \& Littlefield, Lanham, MD, 2006).

[4] Z. Hrepic, D. A. Zollman, and N. S. Rebello, Identifying students' mental models of sound propagation: The role of conceptual blending in understanding conceptual change, Phys. Rev. ST Phys. Educ. Res. 6, 020114 (2010).

[5] H. Eshach, Development of a student-centered instrument to assess middle school students' conceptual understanding of sound, Phys. Rev. ST Phys. Educ. Res. 10, 010102 (2014).

[6] S. Vosniadou, C. Ioannides, A. Dimitrakopoulou, and E. Papademetriou, Designing learning environments to promote conceptual change in science, Learn. Instr. 11, 381 (2001).

[7] R. Beichner, Testing student interpretation of kinematics graphs, Am. J. Phys. 62, 750 (1994).

[8] H. Eshach and I. Kukliansky, Developing of an instrument for assessing students' data analysis skills in the undergraduate physics laboratory, Can. J. Phys. 94, 1205 (2016).

[9] A. Volfson, H. Eshach, and Y. Ben-Abu, Development of a diagnostic tool aimed at pinpointing undergraduate students' knowledge about sound and its implementation in simple acoustic apparatuses' analysis. Phys. Rev. Phys. Educ. Res. 14, 020127 (2018).

[10] J. Clement, Analysis of clinical interviews: Foundations, and model viability, in Handbook of Research Design in Mathematics, and Science Education, edited by A. E. Kelly and R. A. Lesh (Routledge, Abingdon, 2000).

[11] A. Volfson, H. Eshach, and Y. Ben-Abu, When technology meets acoustics: Students' ideas about the underlying principles explaining simple acoustic devices, Res. Sci. Educ. (2020), https://doi.org/10.1007/s11165-019-09913-w.

[12] S. Vosniadou, Conceptual change in learning and instruction: The framework theory approach, in International Handbook of Research on Conceptual Change, 2nd ed., edited by S. Vousniadou (Routledge, New York and London, 2013), pp. 11-30.

[13] H. Eshach, Analysis of conceptual flow patterns and structures in the physics classroom, Int. J. Sci. Educ. 32, 451 (2009).

[14] F. Rabiee, Focus-group interview and data analysis, Proc. Nutrition Soc. 63, 655 (2004).
[15] M. Ponnambalam, Popularization of Physics - the Jamaican experience, Latin Am. J. Phys. Educ. 6, 390 (2012).

[16] R. A. Krueger, Focus Groups: A Practical Guide for Applied Research (Sage, Newbury Park, CA, 1988).

[17] K. Taylor, Weight and centrifugal force, Phys. Educ. 9, 357 (1974).

[18] J. Roche, Introducing motion in a circle, Phys. Educ. 36, 399 (2001).

[19] N. Demirci, A study about students' misconceptions in force and motion concepts by incorporating a web assisted physics program, Turkish Online J. Educational Technol. (TOJET) 4, 40 (2005).

[20] P. Vyas, Misconception in circular motion. Int. J. Sci. Engin. Res. 3, 12 (2012).

[21] A. A. diSessa, Knowledge in pieces, in Constructivism in the Computer Age, edited by G. Forman and P. Pufall (Lawrence Erlbaum Publishers, Hillsdale, NJ, 1988).

[22] A. A. diSessa, A friendly introduction to knowledge in pieces: Modeling types of knowledge and their roles in learning, in Invited Lectures from the 13th International Congress on Mathematical Education, edited by H. Kaiser, M. Forgasz, A. Graven, E. Kuzniak, B. Simmt, and B. Xu (Springer, Switzerland, 2018).

[23] A. A. diSessa, Toward an epistemology of physics, Cognit. Instr. 10, 105 (1993).

[24] M. T. H. Chi, Three types of conceptual change: Belief revision, mental model transformation, and categorical shift, in Handbook of Research on Conceptual Change (Erlbaum, Hillsdale, NJ, 2008).

[25] M. T. H. Chi, R. D. Roscoe, J. D. Slotta, M. Roy, and C. C. Chase, Misconceived causal explanations for emergent processes, Cogn. Sci. 36, 1 (2012).

[26] S. Vosniadou, Conceptual change and education, Hum. Dev. 50, 47 (2007).

[27] A. A. diSessa, N. Gillespie, and J. Esterly, Coherence versus fragmentation in the development of the concept of force, Cogn. Sci. 28, 843 (2004).

[28] M. Ranney, Changing naïve conceptions of motion, Ph.D. thesis, University of Pittsburgh, Learning Research and Development Center, Pittsburgh, PA, 1987.

[29] M. Ranney, Relative consistency and subjects' "theories" in domains such as naive physics: Common research difficulties illustrated by Cooke and Breedin, Memory \& Cognition 22, 494 (1994).

[30] R. M. Dilshad and M. I. Latif, Focus group interview as a tool for qualitative research: An analysis, Pakistan J. Soc. Sci. 33, 191 (2013).

[31] Z. Gurevich, About the Genres of Soviet Circus (Art, Moscow, 1977). 
[32] S. Vosniadou, Conceptual change in learning and instruction: The framework theory approach, in International Handbook of Research on Conceptual Change, 2nd ed., edited by S. Vousniadou (Routledge, New York and London, 2013), pp. 11-30.

[33] S. M. Targ, Force of inertia, in Physics Encyclopedia (Soviet Encyclopedia, Moscow, 1965).

[34] L. D. Landau and E. M. Lifshitz, Theoretical Physics, Book 1 Mechanics (Nauka, Moscow, 1988).

[35] K. A. Putilov, Physics Course Vol. 1 (PhysMatLit, Moscow, 1963).

[36] M. Denscombe, The Good Research Guide for Small-Scale Social Research Projects, 3rd ed. (McGraw-Hill New York, 2007).

[37] H. Eshach and J. L. Schwartz, Sound stuff? Naive materialism in middle-school students' conceptions of sound, Int. J. Sci. Educ. 28, 733 (2006).

[38] K. Fridell and J. Ekberg, Making the invisible visible: a qualitative study of the values, attitudes and norms of radiologists relating to radiation safety, J. Radiological Prot. 36, 200 (2016).

[39] W. Roth, Learning science through technological design, J. Res. Sci. Teach. 38, 768 (2001).

[40] V. Braun and V. Clarke, Using thematic analysis in psychology, Qual. Res. Psychol. 3, 77 (2006).

[41] J. D. Slotta, M. T. H. Chi, and E. Joram, Assessing students' misclassifications of physics concepts: An ontological basis for conceptual change, Cognit. Instr. 13, 373 (1995).

[42] M. T. H. Chi, Commonsense conceptions of emergent processes: Why some misconceptions are robust?, J. Learn. Sci. 14, 161 (2005).

[43] M. T. H. Chi, Conceptual change within and across ontological categories: examples for learning and discovery in science, in Cognitive Models of Science: Minnesota Studies in the Philosophy of Science, edited by R. Giere (University of Minnesota Press, Minneapolis, NM, 1992), pp. 192-186.

[44] I. S. Safuanov, Psychological aspects of genetic approach to teaching mathematics, in International Group for the Psychology of Mathematics Education 15, 121 (2004).

[45] W. K. Ho, Using history of mathematics in teaching and learning of mathematics in Singapore, in Proceedings of the 1st Raffles International Conference on Education, edited by W. K. Ho (RICE, Singapore, 2008), pp. 1-38.

[46] D. Hammer, Misconceptions or p-prims: How may alternative perspectives of cognitive structure influence instructional perceptions and intentions?, J. Learn. Sci. 5, 97 (1996).

[47] N. Bauman, Art of Juggling (Art, Moscow, 1962).

[48] S. Vosniadou, Exploring the relationships between conceptual change, and intentional learning, in Intentional Conceptual Change, edited by G. M. Sinatra and P. R. Pintrich (Erlbaum, Mahwah, NJ, 2003), pp. 377-406. 